\title{
Total Diz Artroplastisi Sonrası Geç Dönemde Gelişen Peroneal Palsi: Vaka Sunumu
}

\author{
Late Peroneal Palsy After Total Knee Replacement: Case Report \\ Kaya Turan ${ }^{1}$, Haluk Çabuk ${ }^{1}$, Osman Görkem Muratoğlu ${ }^{2}$ \\ ${ }^{1}$ İstinye Üniversitesi Tip Fakültesi, Ortopedi ve Travmatoloji Anabilim Dal, İstanbul, Türkiye \\ ${ }^{2}$ Ístinye Üniversitesi Liv Hastanesi, Ortopedi ve Travmatoloji Anabilim Dall, İstanbul, Türkiye
}

Yazışma Adresi / Correspondence:

\section{Kaya Turan}

Aşık Veysel Mah. No:1 Istinye Üniverstesi Liv Hastanesi Esenyurt/İstanbul T: $905332937927 \quad$ E-mail: kaya.turan@istinye.edu.tr

Geliş Tarihi / Received : 27.12.202 Kabul Tarihi / Accepted : 01.06.2021

Orcid:

Kaya Turan https://orcid.org/0000-0002-0547-995X

Haluk Çabuk https://orcid.org/0000-0002-1413-2149

Osman Görkem Muratoğlu https://orcid.org/0000-0003-0049-7937

( Sakarya Tip Dergisi / Sakarya Med J 2021, 11(3):698-701 ) DOI: 10.31832/smj.842501

Öz

Total diz artroplastisi sonrası gelișen peroneal sinir palsi klinik sonuçları önemli derecede olumsuz etklileyen ve nadir görülen bir sorundur. Bu çalıșmamızda 62 yașında sağ dizde ileri derecede gonartroz nedeniyle total diz artroplastisi uyguladığımız hastada ameliyat sonrası 15. günde gelişen peroneal palsinin klinik ve elektrofizyolojik takip sonuçlarını sunuyoruz. Elektromyografik değerlendirmede peroneal sinir motor dalının fibula başı seviyesinde ağır derecede parsiyel aksonal hasarı izlendi. Medikal tedavi ile takibi sonrası 6. Haftadan itibaren klinik iyileşme bulguları başlayan hastada, peroneal sinir eksplorasyon ve nöroliz gerekliliği olmadan, 6 . ayda total klinik ve elektrofizyolojik iyileșme sağlandı. Dejeneratif disk hastalığına bağlı klinik bulgu vermeyen kök basısı olan hastalarda uygulanan total diz artroplastisinde peroneal palsi yatkınlığında artış olabileceği akılda tutulmalıdır.

Anahtar Total Diz Artroplastisi; Peroneal Sinir Palsi; Elektromyografi; Dejeneratif Lomber Disk Hastalı̆̆ı

kelimeler

Abstract

Peroneal nerve palsy that develops after total knee arthroplasty is a rare problem that negatively affects the clinical results. In this study, we present the clinical and electrophysiological follow-up results of peroneal palsy that developed on the 15th postoperative day in a 62-year-old patient who underwent total knee arthroplasty due to severe gonarthrosis in the right knee. Electromyographic evaluation showed severe partial axonal damage at the level of the fibular head of the peroneal nerve motor branch. With the medical treatment, clinical signs of improvement started after the 6th week, without the need for peroneal nerve exploration and neurolysis, total clinical and electrophysiological recovery was achieved in the 6th month. It should be kept in mind that peroneal palsy susceptibility may be increased in total knee arthroplasty performed in patients with lomber nerve root compression without clinical symptoms due to degenerative lomber disc disease.

Keywords Total Knee Arthroplast; Peroneal Nerve Palsy; Electromyography; Degenerative Lomber Disease 


\section{GIIRIŞ}

Total diz artroplastisi sonrası peroneal sinir palsi nispeten nadir görülen klinik bir sorun olup farklı serilerde $\% 0,01$ 4,3 oranlarında bildirilmiştir. ${ }^{1,2}$ Peroneal palsi ekstremite fonksiyonunu ve hastaların klinik sonuçlarını belirgin derecede olumsuz etkilemektedir. Sıklıkla fikse deformitenin cerrahi sırasında düzeltilmesini takiben erken postoperatif dönemde gözlenmektedir. ${ }^{3} \mathrm{Bu}$ olgu sunumumuzda gonartroz nedeniyle total diz artroplastisi ile tedavi edilen hastamızda ameliyat sonrası ikinci haftada gelişen düşük ayak tablosunu tartışmayı amaçliyoruz.

\section{OLGU SUNUMU}

Sağ diz ağrısı nedeniyle polikliniğe başvuran ve konservatif yöntemlerden fayda görmeyen 62 yaşındaki kadın hastamızda yapılan klinik ve radyolojik değerlendirmeler sonucunda sağ diz ekleminin tüm kompartmanlarını etkileyen, tibiofemoral şaft açısının 12 derece varus açılanması gösterdiği gonartroz saptandı (Resim-1). Ek olarak dejeneratif lomber disk hastalığına sekonder lomber spinal stenozu mevcut olan hastanın sağ alt ekstremite nöromotor muayenesinde defisit izlenmedi (Resim-2). Hastamıza arka çapraz bağ kesen (posterior stabilizan) total diz artroplastisi planlanarak cerrahi tedavi spinal anestezi altında erken dönemde herhangi bir komplikasyon izlenmeden uygulandı. Turnike süresi 75, toplam cerrahi süresi 90 dakika olarak kaydedildi. Ameliyat sonrası erken dönemde nöromotor muayenesinde defisit izlenmeyen hastamızın mobilizasyonu sağlanarak, eklem rehabilitasyonuna başlandı ve dördüncü günde 90 derece diz fleksiyonu sağlandıktan sonra yara yerinde sorun izlenmemesi üzerine taburcu edildi. Ameliyat sonrası 14'ncü günde yapılan poliklinik kontrolünde hastamızın bir gün öncesinde başlayan ayak bileği ve parmaklarında ekstansiyon güçsüzlüğü geliştiği izlendi. Takiben yapılan elektromyografik değerlendirmenin common peroneal sinirin fibula başı seviyesinde parsiyel aksonal dejenerasyonu ile uyumlu olduğu görüldü ve hastanın medikal tedavi ile takibi planlandı. Sinir palsine sekonder eklem sorunlarını azaltabilmek için herhangi bir ortez kullanılmadan, ayak bileği ve parmak- lar için eklem hareket açıklığı ve izometrik kas egzersizleri başlandı. Sağ dizdeki şikayetleri tamamen gerileyen hastamızın ameliyat sonrasi altıncı haftadan sonra tedrici olarak öncelikle parmak ekstansör fonksiyonlarında düzelme başladı ve 6. ayın sonunda tamamen ayak bileği ve parmak fonksiyonlarında iyileşme sağlandı (Resim-3). Elektrofizyolojik değerlendirmede de peroneal sinirin rejenerasyonu görüldü. Hastaya bu durumun nadir görülen bir sorun olduğu anlatılarak bilimsel amaçla kişisel verilerinin anonim olarak kullanılması için yazılı onamı alındı.

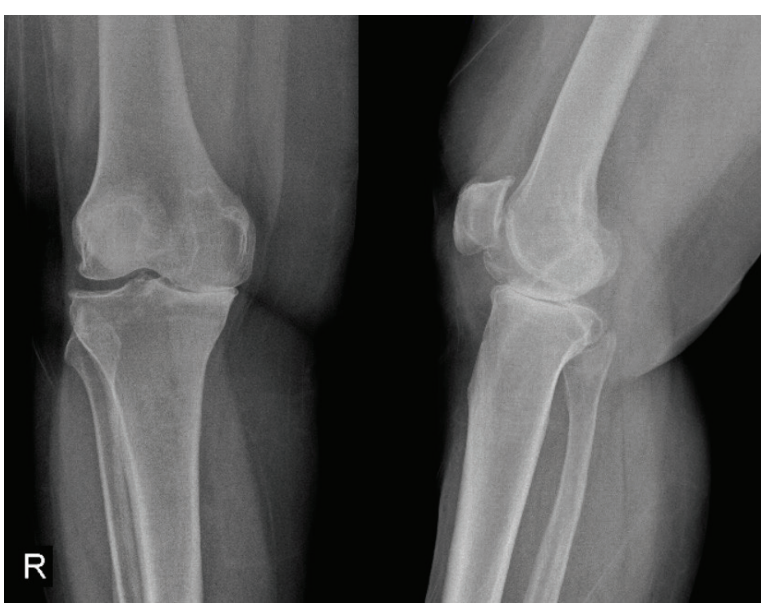

Resim-1: Ameliyat Öncesi Ön-Arka ve Yan Direkt Radyografi

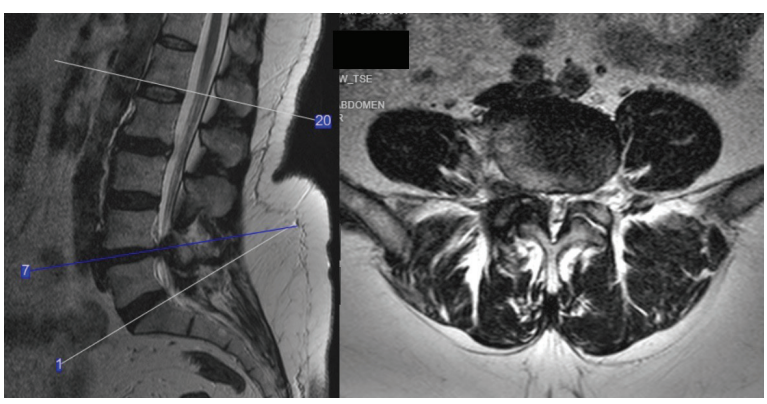

Resim-2: Ameliyat öncesi Să̆ L4-L5 seviyesinde kök basısı ve spinal stenozun görüldüğ̈̈ T2 sekans MR kesitleri 


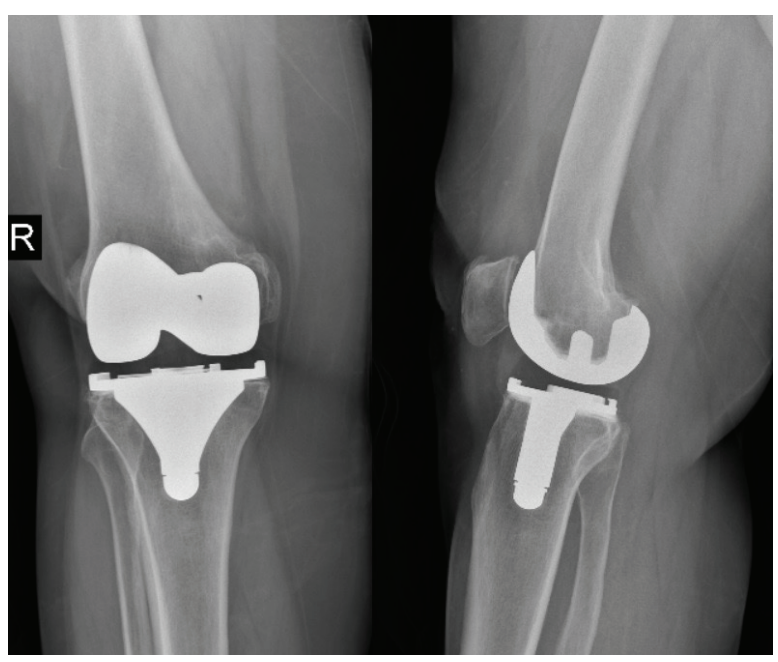

Resim-3: Ameliyat sonrası ikinci yıldaki Ön-Arka ve Yan Direkt Radyografi

\section{TARTIŞMA}

Total diz artroplastisi sonrası sinir hasarları oldukça nadir görülür. Peroneal sinir hasarı ise en sık görülen sinir hasarıdır.4 Fleksiyon deformitesi, ileri derecede valgus deformitesi ve intraartikuler hematom nörolojik hasar ile ilişkili faktörler olmasına rağmen bu risk faktörleri direkt olarak sinir hasarı ile ilişkili değildir. ${ }^{5}$ Preoperatif nöropati ile postoperatif sinir hasarı gelişimi arasında kuvvetli bir bağlantı mevcuttur. Bu durumun proksimal lezyona bağlı (spinal stenoz, dejeneratif disk hastalığı vb.) aksonal akımin azalmasiyla birlikte distal sinirin yaralanmaya daha hassas duruma gelmesi ile açıklanmaktadır. ${ }^{6}$ Hipertansiyon, diyabet, sinir basısı öyküsü, romatoid artrit gibi hastalıklarda rejyonel anesteziye bağlı nöral komplikasyon riski artmaktadır. Aynı zamanda turnike kullanım süresi de sinir hasarı ile ilişkilendirilmiştir. 2 saati aşan turnike uygulamalarında risk artmaktadır. Bu yüzden 2 saatten uzun süren vakalarda 10-30 dakika turnike molası verilmesi önerilmektedir. ${ }^{7}$ Postoperatif dönemde akut olarak gelişen peroneal sinir hasarınının tedavisinde dizin fleksiyonda immobilize edilmesi ve kompresyona neden olacak bandajların gevşetilmesi önerilmektedir. ${ }^{5}$ Böylelikle hastalarda kısmi düzelme izlenmekte ancak çoğu hastada akut tam düzelme gözlenmemektedir. ${ }^{3}$ Krackow ve arkadaşları peroneal sinir eksplorasyonu ve dekompresyonunu erken dönemde üçüncü ayda klinik ve elektrofizyolojik iyileşme görülmeyen olgularda uygulamış ve başarılı sonuçlar bildirmişlerdir. ${ }^{1}$ Takip sırasında düşük ayak mevcut olan hastalarda ayak bileği ortezi kullanılması ve eklem hareket açıklığı egzersizlerine erken dönemde başlanması önerilmektedir. ${ }^{8}$ Total diz artroplastisi sonrası peroneal sinir palsinde tam iyileşme sağlanma potansiyeli farklı serilerde değişen oranlarda bildirilmiştir. Rose ve arkadaşları dışındaki serilerde \%50'den fazla tam iyileşme bildirilmiştir. ${ }^{6} \mathrm{En}$ başta izlenen peroneal disfonksiyonun derecesinin az olması sinirin tamamen iyileşmesine ve daha iyi fonksiyonel diz skorlarının elde edilebilmesine olanak sağlamaktadır. ${ }^{9}$ Olgumuzda peroneal disfonksiyonun geç ve hafif derecede başlaması nedeniyle, tam iyileşmenin altıncı ayın sonunda elde edilebildiğini düşünmekteyiz. Total diz artroplastisi sonrası postoperatif geç dönemde gelişen peroneal sinir palsinde en az 6 ay süreyle konservatif izleme devam edilmesinin, sinir eksplorasyonu ihtiyacını azaltabileceğini düşünüyoruz. 
Sakarya Tip Dergisi 2021;11(3):698-701

\section{Kaynaklar}

1. Krackow KA, Jones MM, Teeny SM, Hungerford DS. Primary total knee arthroplasty in patients with fixed valgus deformity. Clin Orthop Relat Res. 1991 Dec;(273):9-18.

2. Schinsky MF, Macaulay W, Parks ML, Kiernan H, Nercessian OA. Nerve injury after primary total knee arthroplasty. J Arthroplasty. 2001 Dec;16(8):1048-54.

3. Nercessian OA, Ugwonali OFC, Park S. Peroneal nerve palsy after total knee arthroplasty. J Arthroplasty. 2005 Dec;20(8):1068-73.

4. Carender CN. Common Peroneal Nerve Injury and Recovery after Total Knee Arthroplasty: A Systematic Review. Arthroplasty Today. 2020;6.

5. Salih AYAS M, Kalkışım M, Köse A, Gül O. Complications after Total Knee Arthroplasty. In: Bosco Sales Nogueira J, Alberto Dias Leite J, Heráclio Do Carmo Araújo L, Cortez Bezerra M, editors. Knee Surgery - Reconstruction and Replacement. IntechOpen; 2020
6. Rose H, Hood R, Otis J, Ranawat C, Insall J. Peroneal-nerve palsy following total knee arthroplasty. A review of The Hospital for Special Surgery experience. J Bone Joint Surg Am. 1982 Mar 1;64(3):347-51.

7. Nicolaiciuc S, Probst $P$, von Eisenhart-Rothe R, Burgkart R, Hube R. Modern total knee arthroplasty (TKA): With or without a tourniquet? Surg Technol Int. 2019 Nov 10;35:336-

8. Zengin EÇ, Gülman AB. Total diz artroplastisi sonrası görülen peroneal sinir hasarı. J Exp Clin Med, 2013; 133-135

9. Idusuyi OB, Morrey BF. Peroneal Nerve Palsy after Total Knee Arthroplasty. Assessment of Predisposing and Prognostic Factors: J Bone Joint Surg Am. 1996 Feb;78(2):177-84. 